\title{
The Portrait of Reading Strategies Research in Language Education: Policy Recommendations
}

\author{
Ida Puji Lestari
}

University of Brawijaya, Indonesia

Email corresponding author: idapujilestari@ub.ac.id

\begin{abstract}
This article reports on reading research in an English as a foreign language (EFL) context. Literature review as an approach to exploring current theoretical and practical frameworks of reading was used in this paper. Findings suggest that reading, despite seen as a complicated skill to teach in EFL setting, has received multi-facet attentions from scholars. Several studies have investigated reading strategies used by EFL students and the effect of individual differences emerged in the teaching and learning of reading. The results of this review recommend stakeholders to consider reading strategies and learner differences in reading classes as parameters in constructing curriculum for teaching reading in EFL contexts.
\end{abstract}

Keywords: Reading strategies, language education, policy recommendations

\section{INTRODUCTION}

For many years, reading has become the most essential skill to teach in English as a foreign language. Since reading become one of fundamental aspects in enhancing better future life in globalization era, people who want to survive should equip themselves in gaining knowledge and information. Therefore, reading strategies are needed to help readers in comprehending reading texts. Reading strategies become the important way to get an effective reading. This paper reviews some articles related to the importance of reading strategies in comprehending texts and the use of reading strategies in teaching and learning process.

\section{CURRENT RESEARCH OF EFL READING}

Many research discuss the pivotal role of reading strategies in understanding reading texts for learners. Takeuchi and Ikeda (2006) state strategy instruction by various methods has been implemented in many countries due to the use of strategies has been considered to be one of the important factors for successful language learning. Therefore, they attempt to clarify the possible differences in the learning process of reading strategies during the strategy instruction between EFL learners at a higher profeciency level and those at a lower level. Portfolios were used as a data collection method in addition to a training tool. The finding shows that in strategy instruction, rather than giving abstract explanations, concrete examples of effective strategy use drawn from learners with higher proficiency could be presented to learners with lower proficiency. At the phase of introducing strategies, for instance, the conditions in which strategies can be used effectively and the combination in which more than one strategy can be used together could be presented by providing ample examples drawn from portfolios written by the higher proficiency group. At the phase of evaluating the usefulness of strategies, learners could be trained to check the degree of comprehension by using the methods observed in the higher proficiency group. Also, learners could be encouraged to apply the same strategies again in a 
different way to different situations, as was observed in the portfolios of the higher proficiency group.

Lin, et al. (2009) state that the effective use of reading strategies has been recognized as an important way to increase reading comprehension. They investigated EFL learners' online reading strategies and the effects of strategies use on comprehension. To fulfil the purpose of the study they created a Web-based reading program that is called as English Reading Online. The findings shows that the use of support strategies dominated the strategy use and contributed to most of the comprehension gains, but an exclusive dependence on support strategies did not successfully predict the increase in scores on main ideas and details when the students were reading more challenging texts. On the whole, the use of global strategies significantly contributed to better comprehension, especially for low proficiency students.

Botsas and Padeliadu (2003) provide an analysis of goal orientation parameters with respect to reading comprehension strategy use for students with and without reading difficulties(RD). Non-RD students appeared to be more mastery oriented and less performance avoidant compared to RD ones. Also, non-RD students used, more, deeper, more sophisticated and complex ones compared to those of RD students (who used fewer and more surface strategies). Non-RD children appeared to metacognitively monitor their comprehension process while their RD classmates were either ignorant of the existing comprehension problems or bridged meaning gaps in inappropriate ways.

\section{READING STRATEGY RESEARCH IN ENGLISH CLASSES}

The use of reading strategies is catagorized into the use of reading strategies in teaching reading comprehension in term of reading instruction and the use of reading startegies in learning process. Miriam (2004) reports results of two sequential and interrelated studies that examined the efficacy of combining two models of reading strategy instructions namely reciprocal teaching and direct explanation. The reported studies were designed to determine the effectiveness of combined strategy instruction incorporated in school curricula in promoting strategic rading while fostering students ability to perform reading comprehension task that require high levels of knowledge construction. The findings of the study suggest that combined strategy instruction may be beneficial in providing students with tool that will enable them to apply higher order cognitive processes while they learn from texts.

Jumenez et al. (1996) examine the strategic reading processes of 8 bilin- gual Latina/o children who were identified as successful English readers. For comparative purposes, two smaller samples were in- cluded-3 monolingual Anglo students who were successful English readers and 3 bilingual Latina/o students who were less successful English readers. Next, Sziabowski (2008) state reading strategies need to be integrated into class- room instruction rather than taught as a separate entity. The underlying principle is that all students need to speak, read, reason,investigate, conduct inquiry, and write about the concepts in each discipline. She used a technique called SLAMS (Sentence, lines, Answer, Mechanics, Support) for sixth grade students in science class.

Kolic-Vehovec et al. (2008) identify dominant goal orientation patterns in university students, define their motivational profiles and their reading strategy use. The results of cluster analysis showed that four groups of students could be differentiated according to their goal orientation: mastery, mastery - performance, performance -work-avoidance, and workavoidance goal orientation groups. A K-Means cluster analysis is was performed in order to classify the students according to their goal orientation. The findings shows that groups with high mastery orientation had more adaptive motivational profile and more adequate reading strategy use than groups with high work-avoidance orientation. 
Malcolm (2009) states that skilled readers are often characterized as more metacognitively aware than less skilled readers. This questionnaire study of 160 students at a medical university in Bahrain compared reported academic reading strategy use of readers at varying initial English proficiency level and year of study. While all students reported high use of strategies overall, significant differences were found in reported use of metacognitive strategies in general and specific strategies related to translating from English to Arabic. Students of low initial English proficiency and those in their first year reported translating more, while upper year students translated less and used more metacognitive strategies. Compared to findings in previous studies using the same self-report questionnaire, reported reading strategy use was generally higher and more similar to other academic readers in an EFL setting than L1 and L2 readers in a US college. Differences in strategies related to translating suggest an area for further investigation.

Akyel and Ercetin (2009) investigated the strategies used by advanced learners of English while reading a hypermedia document in order to determine whether they are essentially different from those reading strategies reported in the literature for printed texts. Moreover, the role of prior knowledge about the topic was explored in relation to strategy use. Data were collected from 10 advanced learners of English through think-aloud protocols. Results indicate that processing strategies used by advanced learners of English in hypermedia reading are not essentially different from those reported for printed texts. However, certain processing strategies are not used in hypermedia reading. Moreover, strategies used in utilizing annotations and navigating through the text were identified. Finally, readers with high prior knowledge used certain cognitive and metacognitive strategies more frequently. However, low prior knowledge readers were able to compensate for their lack of prior knowledge by using annotations that provided background information about the topic and by navigating through the text in a coherent manner.

Afterwards, Kim and Park (2011) investigates adult English language learners' readingstrategy use when they read online texts in hypermedia learning environments. The learners joined the online Independent English Study Group (IESG) and worked both individually and collaboratively. This qualitative case study aims (a) to assess college-level ESL learners' use of reading strategies for online second language (L2) texts and (b) to examine their use of hypertext and hypermedia resources while they read online L2 text. The seven strategies were (a) usin $g$ hype rmedia, (b) using computer applications and accessories, (c) dialoguing, (d) setting up reading purposes and planning, (e) previewing and determining what to read, (f) connecting prior knowle dge and exper iences with texts and task s, and $(\mathrm{g})$ in ferring. The first two strategies were unique to online readings; the five remaining strategies apply to both online readings and paper-based text readings. The findings also revealed that "hybrid" online reading emph asized participants' vari ous reaction patterns and preferences in their hypermedia learning environments.

Then, Akyol and Ulusoy (2010) determine pre-service teachers' use of reading strategies in their own readings. In addition, pre-service teachers' use of these strategies in their future teaching practices was also investiga ted. The subjects for t his study were 505 pre-service teachers enrolled in one of the major universities in Ankara. The results of the study revealed that pre-service teachers employed 28 out of 38 reading strategies most of the tim e, but in terview results illustrated that they reported using very limited scope of reading strategies. An interesting finding in this study was that all subjects accepted the responsibility to teach and improve their future students' reading skills.

Next, Urlaub (2012) states that reading and discussing literary texts in a second language (L2) is a significant component of intermediate and advanced level collegiate language education. However, in spite of more attention to the role of literary texts in L2 instruction, the function of reading strategy instruction to teaching literary reading in the L2 has remained 
unaddressed. This article investigates the impact of the reading comprehension strategy of generating questions on literary reading development in the L2. The results suggest that teaching language learners how to generate questions vis-a ` -vis texts improves their ability to critically read literary texts in the second language.

Sporer, et al (2014) use reciprocal teaching (RT) was combined with specific selfregulation procedures to promote the reading comprehension of fifth grade students. Twenty four classes with N 1/4 534 students were assigned to RT plus strategy implementation procedures (RT + SIP), RT plus outcome regulation procedures (RT + ORP), RT plus strategy implementation and outcome regulation procedures ( $\mathrm{R} \mathrm{T}+\mathrm{SRL})$, or RT without explicit instruction in selfregulation. At maintenance students assigned to the three self-regulation conditions out performed RT students according to a standardized measure of reading comprehension. $\mathrm{R} \mathrm{T}+$ SIP and RT + SRL students out performed RT as well as RT + ORP students using a measure of reading strategy performance. However, reading comprehension was only mediated by strategy performance under the RT + SRL condition. Among students assigned to the RT + ORP condition, an improvement in reading motivation between pretest and posttest and between posttest and maintenance was observed

Denton, et al. (2015) examine individual differences in adolescents' reading comprehension strategy use related to reading proficiency, grade level, and gender, and investigate factor structure and psychometric properties of a newly-develop scenario-based-self report survey. They also develop Contextualized Reading Strategies Survey (CREss) to measure self-reported reading strategy use for students in middle and high schools. The result are reported in three major sections, first they describe Exploratory Factor Analysis (EFA) and Confirmatory Factor Analysis (CFA). Next, they present result related to reliability and validity . Finally, they evaluate differences in reported strategy use for subgroup based on reading proficiency, grade level, and gender. The findings shows students at higher levels reported greater use of evaluation/integration and regulation strategies than those in lower grades. Females reported higher use of all strategy types than males. In my opinion this articles is too complex and the research questions are not well-structured, it is better if one number represent one question.

\section{CONCLUSION}

After reviewing some articles related to the reading strategies, the writer decides to use an article written by Akyol \& Ulusoy (2010) as the replicated article based on some reasons. Firstly, the studies has a good organizational writing format and clear research questions. Then, it has understandable data analysis to answer those research questions. Next, the writer wants to verify the result of research finding by using the same method but in different sujects, location, and period. It means the writer wants to see the result of research finding is still remain the same or different. Finally, the writer wants to strengthen the evidence of previous research finding related to the use of reading strategies and content area reading courses.

\section{REFERENCES}

Alfasi, M. 2004. Reading to Learn: Effects of Combined Strategy Instruction on High School Students. Journal Educationa Research. Vol.97 (4) :171

Akyel, A., \& Ercetin, G. 2009. Hypermedia reading strategies employed by advanced learners of English. Sciencedirect: Teaching and Teacher Education, vol. 37. p.136-152

Akyol, H., \& Ulusoy, M. 2010. Pre-service teachers' use of reading strategies in their own readings and future classrooms. Sciencedirect: Teaching and Teacher Education, vol. 26. p. $878-884$ 
Botsas,G. \& Padeliadu,S. 2003. Goal orientation and reading comprehension strategy use among students with and without reading difficulties. Sciencedirect:International Journal of Educational Research Vol. 39 p.477-495

Denton, CA. Walter, CA., York, Swanson Kulesz, \& Francis. 2015. Adolescents' use of reading comprehension strategies: Differences related to reading proficiency, grade level, and gender. Learning and Differences. Vol.37. p.81-95

Huang, Chern, Lin. 2009. EFL learners' use of online reading strategies and comprehension of texts: An exploratory study. Sciencedirect: Computers \& Education Vol.52 p.13-26

Ikeda, M \& Takeuchi,O. 2006. Clarifying the differences in learning EFL reading strategies: An analysis of portfolios. System Vol. 34 p. 384-398

Jimenez, R.T., Garcia, G.E., \& Pearson, P.D., 1996. The Reading Strategies of Bilingual Latina/o Students Who Are Successful English Readers: Opportunities and Obstacles Reading Research Quarterly, Vol. 31, No. 1, pp. 90-112

Kim \& Park. 2011. Reading-strategy use by English as a second language learners in online reading tasks. Sciencedirect: Computers \& Education Vol.57 p.2156-2166

Kolic-Vehovec, S., Roncevic, B., \& Bajzanski, I. 2008. Motivational components of selfregulated learning and reading strategy use in university students: The role of goal orientation patterns. Sciencedirect: Learning and Individual Differences Vol.18. p. 108113

Malcom,D. 2009. Reading strategy awareness of Arabic-speaking medical students studying in English. System Vol. 37 p. 640-651.

Sporer, N. \& Schunemann,N. 2014. Improvements of self-regulation procedures for fifth graders ' reading competence: Analyzing effects on reading comprehension, reading strategy performance, and motivation for reading. Sciencedirect: Learning and Instruction Vol.37. p. 147-157

Sziabowski, C. 2008. Science SLAMS - A reading strategy for answering open-ended questions. Science Scope, Vol. 32, No. 3. pp. 53-56.

Urlaub, P. 2012. Reading strategies and literature instruction: Teaching learners to generate questions to foster literary reading in the second language. System Vol. 40 p. 296-304 